\section{Comparing and explaining the trajectories of first and second language acquisition: in search of the right mix of psychological and linguistic factors}

When you compare the behavior of two different age groups which are trying to master the same sensori-motor or cognitive skill, you are likely to discover varying learning routes: different stages, different intervals between stages, or even different orderings of stages. Such heterogeneous learning trajectories may be caused by at least six different types of factors:

(1) Initial state: the kinds and levels of skills the learners have available at the onset of the learning episode.

(2) Learning mechanisms: rule-based, inductive, connectionist, parameter setting, and so on.

(3) Input and feedback characteristics: learning stimuli, information about success and failure.

(4) Information processing mechanisms: capacity limitations, attentional biases, response preferences.

(5) Energetic variables: motivation, emotional reactions.

(6) Final state: the fine-structure of kinds and levels of subskills at the end of the learning episode.

This applies to language acquisition as well. First and second language learners probably differ on all six factors. Nevertheless, the debate between advocates and opponents of the Fundamental Difference Hypothesis concerning L1 and $\mathrm{L} 2$ acquisition have looked almost exclusively at the first two factors. Those who believe that $\mathrm{Ll}$ learners have access to Universal Grammar whereas L2 learners rely on language processing strategies, postulate different learning mechanisms (UG parameter setting in $\mathrm{L} 1$, more general inductive strategies in 12 learning). Pienemann opposes this view and, based on his Processability Theory, argues that L1 and L2 learners start out from different initial states: they come to the grammar learning task with different structural hypotheses (SOV versus SVO as basic word order of German).

However, acquisition routes may diverge in response to the other types of causal factors as well. Language input, which may vary widely between language learning situations, is a case in point. For example, M. Kempen, Gillis and Wijnen (in press) have observed that, in Dutch, childdirected speech contains an abundance of sentence-final non-finite verbs with very transparent meanings (referring to concrete actions). They suggest that this input feature renders such verbs much more salient than finite verbs in sentence-initial positions. This saliency, they argue, is one of the factors contributing to the high frequency of non-finite verbs at the end of the children's own utterances. Although
GERARD KEMPEN

Experimental and Theoretical Psychology Unit, Leiden University, PO Box 9555, 2300 RB Leiden, The Netherlands.

E-mail: kempen@rulfsw.leidenuniv.nl

I have no pertinent data at hand, it seems likely that similar characteristics are less prominent in the language input received by L2 learners of Dutch. On the assumption that these contingencies hold for German as well, the prediction follows that SOV as an initial structural hypothesis is more likely in L1 than in L2 learners of German.

This contrast may be sharpened by additional differences between $\mathrm{L} 1$ and $\mathrm{L} 2$ learners as regards their information processing capabilities (cf. the fourth factor in the above list). In comparison with young children, $\mathrm{L} 2$ learners have available a more diversified "lexicon" of concepts, including concepts not only for concrete actions but also for abstract states, intentions, temporal relationships, etc. This helps them to recognize, in the language spoken in their environment, verbs designating such abstract concepts - among them the modal and copula verbs. These verbs often occupy early positions in a sentence. Wijnen (in press) and $\mathrm{M}$. Kempen et al. indeed observed that the first finite verbs produced by Dutch children in sentence-initial positions are not the inflected forms of the non-finite verbs they have acquired earlier (i.e. those designating concrete actions), but originate from a novel vocabulary of "noneventive" (abstract, state) verbs. Since L2 learners have already acquired the abstract concepts underlying the latter verbs at the onset of the learning episode, they are expected to discover the verb-second rule of German at an earlier stage than L1 learners.

Arguments and observations like the above do not provide a complete account of the differences between the German L1 and L2 acquisition trajectories discussed by Pienemann. What they do bring out is the role that nonsyntactic factors play in the process of acquiring the syntactic rules of a language. This role should be acknowledged in accounts that appeal to syntactic factors, whether in terms of Universal Grammar or Processability Theory.

Pienemann is right in pointing out that the explanations in terms of (limited) access to Universal Grammar that have been proposed for the two acquisition trajectories are unsatisfactory (see the third section). However, his own account based on Processability Theory is not unproblematic either. In the first section (subsection entitled "Principles of processability"), Pienemann assumes that word order of the phrases that have been attached to an S-node, is arranged by a specialized processing module called $\mathrm{S}$ procedure. One of the word order rules (introduced in the second section, "second language development") is R1. It expresses the structural hypothesis (SVO) that L2 learners 
are supposed to entertain initially, that is, at the first acquisition stage. This implies that the S-procedure must be available at that early point in time. However, at the end of the second section, Pienemann writes "that the S-procedure is hypothesised to become available at level 5 of the processability hierarchy", in fact, close to the end of the learning episode. This assumption, which also figures in Table 1 , is needed in order to explain the relatively late appearance of Subject-Verb inversion in L2 utterances (and, in the third section, for the late emergence of finite verbs and their verb-second placement). I cannot escape the conclusion that, in the present version, Processability Theory is internally inconsistent.
If asked my personal opinion of the explanation of similarities and differences between $\mathrm{L} 1$ and $\mathrm{L} 2$ acquisition trajectories, I would suggest that psychological factors such as those revealed by the studies cited above deserve serious consideration.

\section{References}

Kempen, M., Gillis, S., \& Wijnen, F. (in press). Dutch children and their mothers' infinitives. Proceedings of GALA 1997.

Wijnen, F. (in press). Functionele categorieën in Nederlandse kindertaal. Nederlandse Taalkunde. 